\title{
Human capital spillovers in Dutch cities: consumption or productivity?
}

\author{
Viktor A. Venhorst ${ }^{1}$
}

Received: 2 September 2015 / Accepted: 27 February 2016 / Published online: 22 March 2016

(C) The Author(s) 2016. This article is published with open access at Springerlink.com

\begin{abstract}
We study the recursive relationship between the ability of Dutch cities to attract recent graduate human capital to their labour-or housing markets and a city's skills structure, using a comprehensive dataset and a novel operationalisation strategy. We disentangle production and consumption spillovers by separating out human capital employed in a city's labour market and human capital present in a city's resident population, respectively. We do so for both the recent graduates flowing into Dutch cities to find work and a residential location, as well as for the incumbent workers and population. We control for the effects of a city's skills endowments, its (non-) economic characteristics and those of other relevant cities. We find positive effects of a relatively strong graduate labour market inflow on the share of higher and scientific-level jobs. Production spillovers therefore predominantly occur among the higher skilled. Contrary to the higher educated incumbent population, which appears to prefer high skilled services, recent graduate inflows to residential areas have positive effects on the share of jobs requiring lower and medium skills. Consumption spillovers from graduate residential inflows thus occur between higher and lower skilled.
\end{abstract}

JEL Classification J24 $\cdot \mathrm{J} 21 \cdot \mathrm{J} 61 \cdot \mathrm{R} 23 \cdot \mathrm{I} 25$

\section{Introduction}

The presence of human capital in regions and cities is widely regarded as conducive to development and economic growth. Highly skilled individuals, using the urban

Viktor A. Venhorst

v.a.venhorst@rug.nl

1 Faculty of Spatial Sciences, University of Groningen, PO Box 800, 9700 AV Groningen, The Netherlands 
density to share knowledge and to learn, promote productivity increases (Lucas 1988; Krugman 1991). Potentially, cooperating and sharing the city market place with such highly skilled individuals has beneficial effects for other skills groups. These benefits may materialise through production and consumption spillovers. Production spillovers occur when complementarities are sufficiently strong, such that an increase in demand for highly skilled workers also leads to an increase in opportunities for other higher or less-skilled employees. It has been shown that lower skilled workers benefit from learning in dense urban environments (Glaeser 1999; Jovanovic and Rob 1989). Further, a growth in low-skilled services, as a result of consumption spillovers, has been related to the presence of a highly educated incumbent population (Sassen 2001; Glaeser et al. 2001; Glaeser and Gottlieb 2006). Through such mechanisms, the presence of highly skilled individuals in cities may boost opportunities for all skills groups.

There is a strong focus among local policymakers on attracting and retaining graduate human capital (see Venhorst et al. 2011b for an overview for the Dutch case), with the aim of capturing these benefits for the regional economy. However, there is little knowledge on how this affects a city's skills structure in the longer term. Does the presence and inflow of highly skilled workers and inhabitants create or reduce the opportunities for only such highly skilled groups, or are there also effects on other skills groups? What is the most important mechanism that drives these effects: productivity or consumption spillovers? Should policymakers focus on retaining or attracting graduates to the local labour market, or is there also a role for the residential market? In this paper, we study the structural determinants of the skills structure of Dutch cities. We focus specifically on the interaction between the employment skills structure and the inflow of graduate human capital. We apply a unique dataset that allows us to control for the existing city stocks of human capital and other factors that may influence the city's skills structure.

In order to address both production and consumption spillovers, graduate human capital inflow is operationalised in terms of labour market inflow relative to housing market inflow. Our dataset allows us to distinguish between graduates starting a career within a city's labour market and graduates moving into the city's residential areas. Likewise, an important feature of this study is our differentiation between the exact location of jobs by qualification level and the location of the resident population by education level. We argue that such a distinction is instrumental in disentangling consumption and productivity effects of both existing stocks of resident and working individuals as well as recent graduates. As Venhorst and McCann (2015) demonstrate, among graduates job-place mobility is consistently larger than residential mobility, with especially the latter dropping substantially as the years relative to the moment of graduation go by.

Secondly, we use the skills level required by employers. This may be a better measure of a city's skills structure as workers with long tenures tend to progress to higher level jobs through on-the-job learning or additional training (Schlitte 2010) than their initial education level would suggest. As such, this approach allows us to look at how skills are utilised.

Thirdly, little is known about how a city's skill structure is related to the characteristics of other nearby cities, or those with which a commuting tie exists. This is particularly important when studying employment and population interactions on 
lower spatial scales. Since cities can be regarded as perfect open economies (Nijkamp and Poot 1998), it is important to take into account the effects of nearby areas. For example, it has been demonstrated that nearby large cities can create substantial backwash effects (Partridge et al. 2007a, b) and that nearby residential amenities may have effects on a firm's location choice (Boarnet 1994; Gottlieb 1995).

This paper is structured as follows. In Sect. 2, we discuss the main findings that have emerged from the literature. This is followed by a discussion on the approach taken in this study. In Sect. 3, we introduce our dataset covering 287 Dutch municipalities and discuss the operationalisation of our variables. In Sect. 4, we discuss the results from our empirical analysis and Sect. 5 presents the main conclusions.

\section{Literature review and approach}

\subsection{Human capital and regional economic development}

It is widely recognised in the literature that, in addition to private benefits from human capital accruing to individual workers, there are social benefits to having a sizeable pool of individuals with high human capitals within a region (Lucas 1988; Rauch 1991). It is argued that the beneficial effects of human capital are higher in dense economic environments such as cities because face-to-face interactions between individuals are less costly and happen more frequently. Such interactions speed the transmission of new ideas and knowledge in a regional economy. An overview of the theoretical work on the mechanism involved can be found in Duranton and Puga (2004). Moretti (2004a) gives an overview of empirical research on these human capital spillovers. Essentially, as workers become more productive in these urban environments, higher net wages will be paid by firms, thus attracting more workers. City land rents then increase to the point where an individual migrant faces the same real wage level across the economy, thereby bringing migration towards the city to a halt (Moretti 2004b). Through this process, the externality of human capital is internalised within the economy.

Human capital spillover is the mechanism through which the human capital stock exerts its effect on the economy. Assuming the process of internalisation described above, spillovers are often studied through the development of individual wages and land rent premiums in relation to regional aggregate human capital levels, using Mincerian frameworks (Rauch 1991; Acemoglu and Angrist 2000; Moretti 2004a, c; Glaeser and Maré 2001; Shapiro 2006). The wage effect of a relatively large supply of highly skilled workers consists of two components: a supply effect and a spillover effect. If complementarities between skill levels in the labour market are sufficiently high, and substitution between the skill levels is low, an oversupply of highly skilled workers will lead to lower wages (through lower marginal productivity) for this group. Higher wages for the other skills groups within the local economy can be expected as a result of the high complementarities. The spillover also serves to increase general productivity, for example through learning in dense environments. Any empirically measured effect of a region's endowment of highly skilled inhabitants on skill-specific wage rates is therefore the sum of these two effects (Moretti 2004b). The positive effects on wages from the presence of a large stock of highly educated workers, as 
are generally found in the literature, are an indication that the spillover effect is sufficient to overcome any negative supply effect. However, greater insight is needed into the underlying mechanism. Broersma et al. (2015) show, for example, that, for the Netherlands, an important component of the wage spillover effect results from interactions between individuals within firms rather than interactions between individuals co-located within a region.

Wage and land rent signals may, however, be distorted by institutional issues related to the functioning of labour and housing markets such as central wage bargaining and planning restrictions on real estate development. Central wage bargaining negates regional differences in productivity levels. Constraints on local real estate development make the responses of land rents to productivity shocks hard to identify. A number of studies have therefore focused specifically on the effect of human capital endowments on either skill-specific or overall employment growth. ${ }^{1}$

Human capital spillovers do not necessarily translate into employment growth. Combes et al. (2004) point out that technological development may be labour saving, or that labour supply may be inelastic. Suedekum (2009) notes that the employment effects of human capital spillovers may be driven by complementarities between skills groups. Also, a relatively skill-abundant local economy may, as a result of the negative supply effect on wage rates, attract fewer additional highly skilled workers (Suedekum 2009). A variety of studies have, however, demonstrated that high human capital endowments do have positive effects on subsequent city employment growth (Glaeser and Saiz 2004; Suedekum 2009; Glaeser et al. 1995; Shapiro 2006; for the Netherlands specifically see Marlet and Woerkens 2007).

Other studies have focussed on the effects on different skills groups. For Germany, it was found that the presence of highly skilled workers has positive effects on the employment opportunities for medium and lower skilled workers (Suedekum 2009; Schlitte 2010). Berry and Glaeser (2005), however, note an increasing accumulation of skilled workers in US metropolitan areas that are already well endowed with highly skilled inhabitants. Accumulation, or specialisation, in this context is studied by looking at the coefficient value of the lagged dependent variable in a model explaining levels or shares of human capital in cities. A value that is greater than one (the result in Berry and Glaeser 2005) implies an increasing concentration over time, but is also indicative of an explosive time series. Poelhekke (2006) noted that these results therefore need to be interpreted with some care: the share of skilled individuals cannot increase indefinitely, something the analysis by Berry and Glaeser (2005) suggests. Nevertheless, it was demonstrated that, in the period studied (1970-2000), skilled US cities became more skilled. This, however, was not due to the presence of skilled individuals as such. Rather, as Poelhekke (2006) concludes based on an analysis of the same Berry and Glaeser dataset, other city-specific factors seem to be in play.

Shapiro (2006) also notes that a positive relationship between human capital and city growth may be driven by other factors that affect both, such as amenities or the city's industry structure. Glaeser (1999) has pointed out those cities with high endowments

\footnotetext{
1 Among others, Blien et al. (2006), Glaeser et al. (1992) focus on city-industry employment growth. Their distinction between manufacturing and service-related sectors shows localisation effects similar to those found for human capital endowments elsewhere.
} 
of amenities have grown faster than low-amenity cities. He notes that urban rents have increased faster than wages, suggesting that the desire to live in urban areas has increased for reasons beyond productivity increases. Poelhekke (2006) highlights the importance, as a pull factor in the localisation of skills, of the low-skilled service sector-i.e. the presence of local consumption opportunities. Bils and Klenow (2000) find a positive relationship between educational level and economic growth at the country level, but suggest that causality might in fact run the other way: that economic growth causes an increase in the average regional education level.

Spatial mobility may be a crucial factor in this respect. It has been demonstrated that regional human capital endowments can stimulate growth, as was discussed above. However, equally, human capital has been shown to flow to regions that are doing well (Duranton and Puga 2004; Faggian and McCann 2006, 2008, 2009; Carlino and Mills 1987). This spatial mobility of human capital has consequences for its relationship with regional economic development since structural outflows of human capital can negatively affect innovative capacity (Nijkamp and Poot 1998; Faggian and McCann 2009). Rodríguez-Pose and Vilalta-Bufí (2005) found that job satisfaction and migration measures contributed substantially to explaining regional GDP, over and above the more traditional measures of human capital endowments. Therefore, it seems that attention should be paid not just to existing endowments, but also to what attracts human capital to regions and whether these highly skilled workers are then able to utilise their skills in the regional economy.

Population and regional employment growth are thus found to be strongly related: directly through supply effects and spillovers, but also indirectly as a result of the aforementioned city-specific attractions and amenities. One line of literature has sought to more explicitly take these interrelationships into account, starting with Carlino and Mills (1987). ${ }^{2}$ Following this approach, Boarnet (1994), Boarnet et al. (2005) and Gottlieb (1995) among others have pointed to the role that neighbouring areas play in employment and population growth. Boarnet (1994) highlighted spatial specialisation (working against living) in multi-centric metropolitan areas and finds that employment growth depends on the population growth in nearby residential areas. Gottlieb (1995) demonstrates that firms take the residential amenities in housing locations likely to be of interest to their staff into account in making location decisions, and that this extends to cities within commuting distance. Focussing on population growth, Partridge et al. (2007a, b) show that, for Canada, substantial, both positive and negative, effects may result from being close to larger metropolitan areas. In some cases, suburban areas are able to profit from providing residential opportunities for those working in the larger cities.

From this, we conclude that several factors are relevant in our study into the relationship between a city's skills structure and the inflow of graduate human capital. Firstly, not only existing stocks but also the flows of graduate human capital are important in explaining regional development. Reverse causality may play a role, with human capital being attracted to successful regions and cities. These two variables are therefore

\footnotetext{
${ }^{2}$ Hoogstra et al. (2005) provide an overview of studies based on this methodology. Hoogstra et al. (2011) present a Monte Carlo analysis of the effects of specification choices on the interrelationship between population and employment.
} 
best treated as endogenous. Secondly, it is important to control for factors that may drive both the skills structure and the inflow of graduate human capital. An important insight is that aspects that can be thought of as purely residential amenities may also affect the placement of employment. Thirdly, on the spatial scale of the Dutch city, we can expect strong interrelationships to exist between a city and other places, both close by and within commuting distances. In the next section we discuss how these matters were translated into our econometric approach.

\subsection{Analysing the skills structure in Dutch cities: approach and expectations}

In this study, we focus on the recursive relationship between a city's employment skills structure and the inflow of graduate human capital onto the city's labour and housing markets. Our analysis will be based on a sample of 287 Dutch cities, for which we have data spanning the period 1998-2008. In this section we outline our econometric approach. A discussion of our operationalisation and the dataset can be found in Sect. 3.

The main focus of our analysis is identifying the structural determinants of graduate inflow and a city's skills structure. Therefore, in this paper, we analyse differences between cities, in terms of the spread of skills in total city employment and the inflows of human capital, rather than by considering annual growth rates.

In our modelling strategy, we have to be mindful of a number of potential econometric pitfalls. Firstly, the sought-after relationship is potentially obscured by endogeneity. In a number of similar studies, simultaneity was dealt with by lagging the exogenous variables by a considerable length of time. We model outcomes for the endogenous city-specific skills structure and graduate inflow using exogenous variables with tenyear lags. ${ }^{3}$ We also enter the lagged dependent variable into our models.

We apply a seemingly unrelated regression (SUR) ${ }^{4}$ model, taking into account the correlation that might exists between these equations as a result of endogeneity. We have applied the following specifications. Firstly we have an equation that defines JobHigher/Lower ${ }_{i, t+10}$ - which is total city employment at higher and scientific skill levels, relative to the total number of jobs at medium, lower or elementary levels, in city $i$ at time $t$ :

$$
\begin{aligned}
\text { JobHigher/Lower }_{i, t+10}= & \beta_{0}+\beta_{1} \text { GrWork/Liv }_{i, t}+\beta_{2} \text { WCGrWork/Liv }_{i, t} \\
& +\beta_{3} \text { JobHigher/Lower }_{i, t}+X_{i, t} \theta+\varepsilon_{i, t+10}
\end{aligned}
$$

\footnotetext{
3 The ten-year period applied in this study covers a full business cycle, with a strong recession in 20022003. It is also in line with studies for the USA that are often based on ten-year census intervals. It excludes the ensuing financial crisis. We have included a version of our models based on one-year lags in "Appendix 2" (Model 1B and Model 2B). The results are qualitatively in line with the versions presented in the main text.

4 We use Stata's reg3 routine, with sure option. In line with Suedekum and Blien (2005), we apply analytical weights, using the city population share of the national total. This serves to ameliorate heteroskedasticity related to differences in city size. Estimating the model without analytical weights leads to qualitatively similar results, which are available from the author upon request.
} 
with $i$ denoting the city index, $i=1, \ldots, 287$; and $t$ the year of observation.

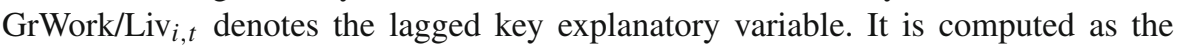
ratio of the inflow of recent graduate human capital into the city's labour market to the inflow of recent graduate human capital into the city's residential area. All other explanatory variables in the model are lagged to the base year and taken to be exogenous. We include a spatial lag of the key explanatory variable (WCGrWork/Liv $i, t$ ) following Boarnet (1994) and Boarnet et al. (2005). ${ }^{5}$ JobHigher/Lower $_{i, t}$ denotes the lagged dependent variable, which is intended to control for persistence in the city skill structure. Matrix $X_{i, t}$ contains the other exogenous variables ${ }^{6}$ for city $i$, such as the education breakdown of the resident population-with the share of medium educated omitted, city size, labour and housing market characteristics and the number of graduates from a local higher education institution, plus spatially lagged values for a number of these variables. We also include year dummies.

The second equation describes the endogenous variable GrWork/Liv $i, t+10$, in which JobHigher/Lower $_{i, t}$ is entered as main explanatory variable. The equation otherwise has a similar structure as the employment skills structure equation, including a lagged dependent variable, and the matrix $X_{i, t}$ containing a set of additional exogenous variables:

$$
\begin{aligned}
& \text { GrWork/Liv }_{i, t+10}=\gamma_{0}+\gamma_{1} \text { GrWork/Liv }_{i, t}+\gamma_{2} \text { WCGrWork } / L i v_{i, t} \\
& +\gamma_{3} \text { JobHigher/Lower }_{i, t}+X_{i, t} \xi+\eta_{i, t+10} \text {. }
\end{aligned}
$$

\section{Operationalisation and data}

In "Appendix 1" a full overview is presented of the variables applied in this study and the data sources used. Also, we discuss there the steps that were taken in constructing the main variables in our database in greater detail. Sample statistics for the main variables are reported in Table 1 below. We have focussed on a subset of 287 larger municipalities out of a national total of 441 (as of January 2009). Our selection was based on the number of inhabitants and data availability. Cities and towns with more than 10,000 inhabitants over the entire study period were selected. The ten-year lags leave us with two years of data. For the main dependent variables we also provide the non-lagged values in Table 1.

\subsection{Main dependent variables}

In this section, we discuss the two main dependent variables in this analysis: city skills structure and the typology of the city in terms of inflow of graduates (leaning towards the labour market or towards the residential areas).

\footnotetext{
5 We note here that Boarnet (1994) has a constraint $\beta_{1}=\beta_{2}\left(\gamma_{1}=\gamma_{2}\right.$ respectively). As an alternative, we treat the spatial lag of the endogenous variable (i.e. the unweighted mean of the variable over all cities with which a commuting relationship exists) as exogenous.

6 We computed the VIF values for all the equations in order to check for multicollinearity. The VIF scores are all within established bounds (VIF $<10)$. Results can be provided upon request.
} 
Table 1 Sample statistics

\begin{tabular}{|c|c|c|c|c|c|c|c|c|}
\hline & \multicolumn{4}{|l|}{$\underline{\text { Year } t}$} & \multicolumn{4}{|c|}{$\underline{\text { Year } t+10}$} \\
\hline & Mean & SD & Min & $\operatorname{Max}$ & Mean & $\mathrm{SD}$ & Min & Max \\
\hline \multicolumn{9}{|c|}{ Graduate inflow on city housing/labour market } \\
\hline GrWork/Liv & 0.68 & 0.47 & 0.00 & 3.61 & 0.78 & 0.48 & 0.00 & 3.35 \\
\hline WCGrWork/Liv & 0.70 & 0.19 & 0.30 & 1.47 & & & & \\
\hline \multicolumn{9}{|c|}{ City stocks of human capital: jobs by skill level (shares) } \\
\hline JobHigher/Lower & 0.30 & 0.42 & 0.02 & 4.60 & 0.32 & 0.32 & 0.03 & 2.89 \\
\hline JobShHigherSk & 18.92 & 13.90 & 2.19 & 82.15 & 21.59 & 12.23 & 3.37 & 74.26 \\
\hline \multicolumn{9}{|c|}{ City stocks of human capital: population education level (shares) } \\
\hline PopShLowEduc & 39.33 & 6.65 & 22.22 & 61.21 & & & & \\
\hline PopShMedEduc (omitted) & 42.16 & 4.07 & 30.17 & 54.09 & & & & \\
\hline PopShHighEduc & 18.50 & 6.67 & 6.00 & 40.16 & & & & \\
\hline \multicolumn{9}{|c|}{ Size of City and surrounding cities } \\
\hline LnPopTot & -1.06 & 0.67 & -2.23 & 1.97 & & & & \\
\hline WNLnPopTot & -0.93 & 0.59 & -2.19 & 0.93 & & & & \\
\hline LnJobTot & -2.11 & 0.87 & -3.99 & 1.33 & & & & \\
\hline WNLnJobTot & -1.84 & 0.76 & -3.65 & 0.31 & & & & \\
\hline \multicolumn{9}{|c|}{ City economic control variables } \\
\hline Shock & 3.30 & 0.85 & 1.57 & 6.02 & & & & \\
\hline FrmSize & 0.93 & 0.31 & 0.33 & 2.29 & & & & \\
\hline Unem & 5.07 & 2.12 & 0.00 & 14.01 & & & & \\
\hline ShLowIncHH & 27.15 & 4.54 & 16.00 & 39.51 & & & & \\
\hline \multicolumn{9}{|c|}{ City amenity control variables } \\
\hline LnHousP & 0.09 & 0.23 & -0.66 & 0.81 & & & & \\
\hline Crime & 6.61 & 3.48 & 0.25 & 21.68 & & & & \\
\hline \multicolumn{9}{|c|}{ Presence of colleges and universities } \\
\hline Grads & 0.15 & 0.56 & 0.00 & 4.59 & & & & \\
\hline WCGrads & 0.55 & 0.18 & 0.12 & 1.30 & & & & \\
\hline
\end{tabular}

Number of cases: 574

Traditionally, measures of human capital are based on the highest education level attained, or the years of schooling completed. However, as Schlitte (2010), among others, has pointed out, this measure does not take into account the effects of onthe-job learning or increased responsibilities as a result of tenure. Alongside this, as Di Pietro and Urwin (2006) point out, employers may increase the skills profile of their labour demands if skills are relatively abundant in their region, assuming that higher skilled employees will be easier to attract and can be trained at lower costs. The resulting patterns of over- and under-education mean that worker education level is not necessarily a good proxy for skill. As an alternative, the 'International Standard Classification of Occupations' (ISCO) job skills levels can be used as an indication of the skills structure of a local labour market. For the reasons outlined above, in this paper, we base our analysis of the city skills structure (endogenous 
variable JobHigher/Lower ${ }_{i, t}$ ) on the ISCO classification, expecting it to better reflect the skills structure of the labour market.

We now turn to our second main variable, GrWork/Liv ${ }_{i, t}$. In this study we measure a city's ability to attract human capital by looking both at recent graduates, i.e. at around 18 months after graduation, starting a job on the city's labour market as well as graduates moving into the city's residential areas, as we are interested in disentangling production and consumption effects associated with these different flows. These graduates may have received their degree from a local college or university (i.e. they are retained) or elsewhere. Simply using the size of these flows or scaling them, for example using city population size, will not identify consumption or productivity spillovers over and above the baseline effect of city size since both residential and labour market oriented flows will be larger for larger cities (Venhorst et al. 2011a). Instead we have computed our second endogenous variable GrWork/Liv ${ }_{i, t}$ to generate the city-specific ratio of labour market inflow to residential inflow of graduates. This variable indicates whether a city's inflow is relatively labour market dominated (values larger than one) or relatively strongly oriented towards residential areas (values below unity). Graduates who are working and living in the same city enter in the nominator as well as the denominator of this variable. A positive $\beta_{1}$ coefficient for this variable in the JobHigher/Lower ${ }_{i, t}$ equation will then signal that cities with a labour market attraction profile will on the longer term exhibit a higher skilled job structure, much like the productivity spillover-driven developments in US cities discussed earlier. Likewise, cities with a more residential oriented inflow will exhibit a labour market skill structure oriented towards elementary to medium skilled workers, presumably in consumer services. A negative $\beta_{1}$ coefficient signals the reverse. In this case, graduate inflows on city labour markets lead to opportunities for elementary to medium skilled workers, whereas cities with a graduate inflow dominated by residential motives feature more opportunities for higher and scientific-level jobs, likely in higher level services.

City-specific employment in terms of the skill levels demanded by the employers is derived from the Working Conditions Survey (WCS) ${ }^{7}$ published by the Dutch Ministry of Social Affairs and Employment. We use the School-leaver Information System (ROA-SIS) dataset ${ }^{8}$ from the Research Centre for Education and the Labourmarket (Maastricht University) and Statistics Netherlands data to compute the flows of graduates towards a city's labour and housing markets (variable "GrWork/Liv"). Comparing the base values of our endogenous variables with the values ten years ahead, it becomes clear that, in our sample of cities, the ratio higher level jobs-lower level jobs has increased slightly. The mean value for GrWork/Liv has increased more substantially, from 0.68 to 0.78 . This indicates that, at least in our sample of cities, the labour market inflows have on average become more important relative to the inflows into the residential market. This might imply that other smaller cities, not included in

\footnotetext{
7 In Dutch: Arbeidsvoorwaarden Onderzoek (AVO). This survey is an annual, from 1992 onwards, representative cross-sectional sample of firms and their employees,. On average, 37,000 employees in 2000 firms are surveyed.

8 On average, higher education graduates are surveyed 18 months after they have graduated from their higher education institution.
} 
this study, over time have become more successful at attracting or retaining graduates to their residential areas.

In order to establish whether our results are driven a denominator effect of sorts, we have also estimated an alternative version of our SUR model, using JobShHigherSk rather than JobHigher/Lower. The variable JobShHigherSk simply measures the share of jobs in the city of higher or scientific level.

\subsection{Exogenous variables}

Based on the literature findings discussed earlier, we introduce a number of exogenous control variables alongside the time lags of the dependent variables. The exogenous variables in both equations include controls for city size, size of neighbouring cities, a set of controls for the city's economic situation and amenity characteristics plus control variables describing the presence of universities. Below, we briefly introduce these variables.

A novel element in this study is separately controlling for the effects on the city's skills structure of the skill levels required for the city's existing stock of jobs (relevant to the productivity effects discussed earlier) and the education level of the city's resident population (in relation to consumption spillovers). In the JobHigher/Lower equation, the lagged dependent variable controls for the existing stocks of jobs by the skill levels required. The education levels of the city's inhabitants (variables "PopShLowEduc" and "PopShHighEduc") are based on Statistics Netherlands data, using the three way (low, the omitted medium and high) ISCED classification. In this study we use the education level of the potential labour force (aged 19-65) by residential area, data which can be derived from the Statistics Netherlands Labour Force Survey. In addition to the effects of the consumption by higher educated residents on low-skilled service industries (Sassen 2001; Poelhekke 2006), Moretti (2004b) and Shapiro (2006) note that a higher educated resident population may uphold certain facilities in cities, alongside exhibiting higher rates of social activity. As such, it will be interesting to see whether the consumption effect of the skills structure of a city's resident population is significantly associated with lower or higher skilled jobs, over and above the effect of the employment skills structure.

In both equations, we control for city size and the size of neighbouring cities. The question is whether the effect of the skills structure in general is significant, given the general demand effect of having access to a large market. In order to separate the effect of tastes and participation from the more general effective demand effect of higher wage levels for the higher educated population, we also enter the proportion of low income households (variable "ShLowIncHH", again based on Statistics Netherlands data). Through this additional control, the variables measuring the resident population's skills structure are 'cleaned' of any income effect and better reflect their different effects on the city's skills structure, through tastes, participation or the relationship with the city's facility structure. The income effect is itself indicative of the role a city's purchasing power plays in determining its skills structure.

Earlier, from the literature, it was concluded that it is important to control for factors that simultaneously influence the presence of human capital, the city's skills structure and employment growth (Shapiro 2006). In many studies, variables are added that 
reflect the economic structure of a city, alongside some assessment of amenity richness of the city or surrounding region. Often natural amenities, such as the vicinity of beaches, are used in this respect. The effect of such amenities on economic conditions has also been criticised (Storper and Scott 2009). Including amenities such as theatres and restaurants assumes that these are indeed valued by the group under study. To avoid this issue, we have decided to use somewhat more general measures reflecting housing costs and crime rates. In line with Gottlieb's (1995) findings, we do not assume that residential amenities only affect the population since firms may well take residential amenities, in potential housing areas for their staff, into account when choosing a production location.

We use the LISA register of firms' data to compute the average firm size (variable "FrmSize") in a city. Larger firms are often assumed to be less economically dynamic (Blien et al. 2006) but may offer a wider range of employment opportunities for different skills groups. We also use the LISA dataset to compute the variable "Shock" that functions as a control for nationwide production shocks. Following Katz and Murphy (1992), we weigh national single-digit NACE sector-specific yearly employment growth by the city's sectoral structure. In other words, we reweight the national growth rate by the city's employment structure. This variable first controls for effects related to having a favourable, in terms of the business cycle, sectoral structure on the city's skills structure. Given the growth in the Dutch service sector in the period studied, we would expect that this to largely translate into employment opportunities for the higher skilled. Second, it acts as a general control for a city's industry structure. Data on housing prices ("LnHouseP"), crime rates ("Crime") and unemployment rates ("Unem") are all computed from Statistics Netherlands data.

We include the number of graduates that left university or colleges of higher education by city (the variable "Grads"). Naturally, this variable is 0 for all cities that do not have such institutions within their borders. This variable controls for the effect on the skills structure and graduate inflow of the presence of such institutions in cities.

Given the findings in Boarnet (1994) and Boarnet et al. (2005), we include spatial lags of some of the key endogenous and exogenous variables in our analysis. Florax and Folmer (1992) also recommended such an approach when faced with substantive spatial spillovers. The spatial scale of Dutch cities is relatively small and, as a result, strong interrelationships can be expected to exist between them. Boarnet et al. (2005) compare various spatially weighted matrix specifications in the context of modelling population and employment interactions. They conclude that there is no single best fit, and that the substantive interpretation of results is best served by using a spatially weighted matrix that leaves room for interpretation. In this study we therefore apply a row-normalised commuting matrix to compute the spatial lags of the relevant exogenous variables. We construct our row-normalised spatial interaction matrix using data on the $2009^{9}$ commuting flows, but including only those flows of a substantial size.

\footnotetext{
9 Commuting matrices for 2006 through to 2009 are currently available from Statistics Netherlands. As our analysis covers 1998-2008, we have selected the 2009 matrix to avoid endogeneity issues. Further, our focus is on the more substantial flows, and these do not vary over time to a large degree. We have also recoded them using dummy values, leading to a rather general system of important flows, and so the year chosen should not substantially affect the results.
} 
The off-diagonal elements of the non-normalised base matrix were designated 0 if the flow was smaller than 100 commuting individuals and 1 if the flow was larger. Using a time-varying matrix with values reweighted according to flows would, in our view, introduces substantial levels of endogeneity in the specification, and therefore, after row-normalising, we do not reweight the spatially lagged variable according to flow size. Rather, the spatially lagged variable simply reflects the average value for municipalities with which a commuting relationship exists. All variables with the prefix 'WC' are computed using this matrix.

\section{Results}

In Table 2, the results for our SUR model are presented. The model consists of an equation describing the city-level employment distribution by skill level required (higher relative to lower, or "skill ratio"), and one for the city inflow of graduates onto the labour market, relative to their inflow onto the housing market. This specification is referred to as Model 1. We also report Model 2, where the "skill ratio" was replaced by the simple share of higher and scientific-level jobs in city employment. Model 2 is added as a robustness check, which looks at the results for the higher level jobs in isolation from a potential denominator effect. ${ }^{10}$ The coefficients for all the equations are jointly significant and the $R^{2}$ values for both equations are at an acceptable level. We start our discussion by considering the results for the key variables in the analysis. This is followed by a discussion of the results for the other exogenous variables.

\subsection{The relationship between skills structure and graduate human capital inflows}

Our model found a positive $\beta_{1}$ coefficient for the variable GrWork/Liv in the JobHigher/Lower equation. This implies that cities characterised by a relatively strong inflow of recent graduates onto their labour markets have higher shares of higher and scientific level jobs. Likewise, cities with a relatively strong inflow on their housing markets exhibit higher shares of elementary to medium share workers. This can be interpreted as production spillovers amongst the higher skilled and consumption spillovers between the higher and lower skilled. This in itself is in line with the findings for the USA (accumulation of the skilled in certain cities), but it is predominantly true for cities which are attractive work destinations for graduates. Consumption spillovers, likely pertaining to lower skilled service jobs, are thus found to be relevant as well, but in residential-type cities.

Looking at the reverse relationship, i.e. the effect of JobHigher/Lower on GrWork/Liv, we find a negative effect, which is only significant at the $10 \%$ level. The result is confirmed in the Model 2 specification. Cities with wider job opportunities at the higher and scientific levels were found to be relatively well positioned to draw in graduate human capital for their labour markets (Venhorst et al. 2011a).

10 We note here that running Model 2 with the share of elementary to medium skilled jobs mirrors the result for the higher skilled, as JobShHigher $=(100-$ JobShLower $)$. 


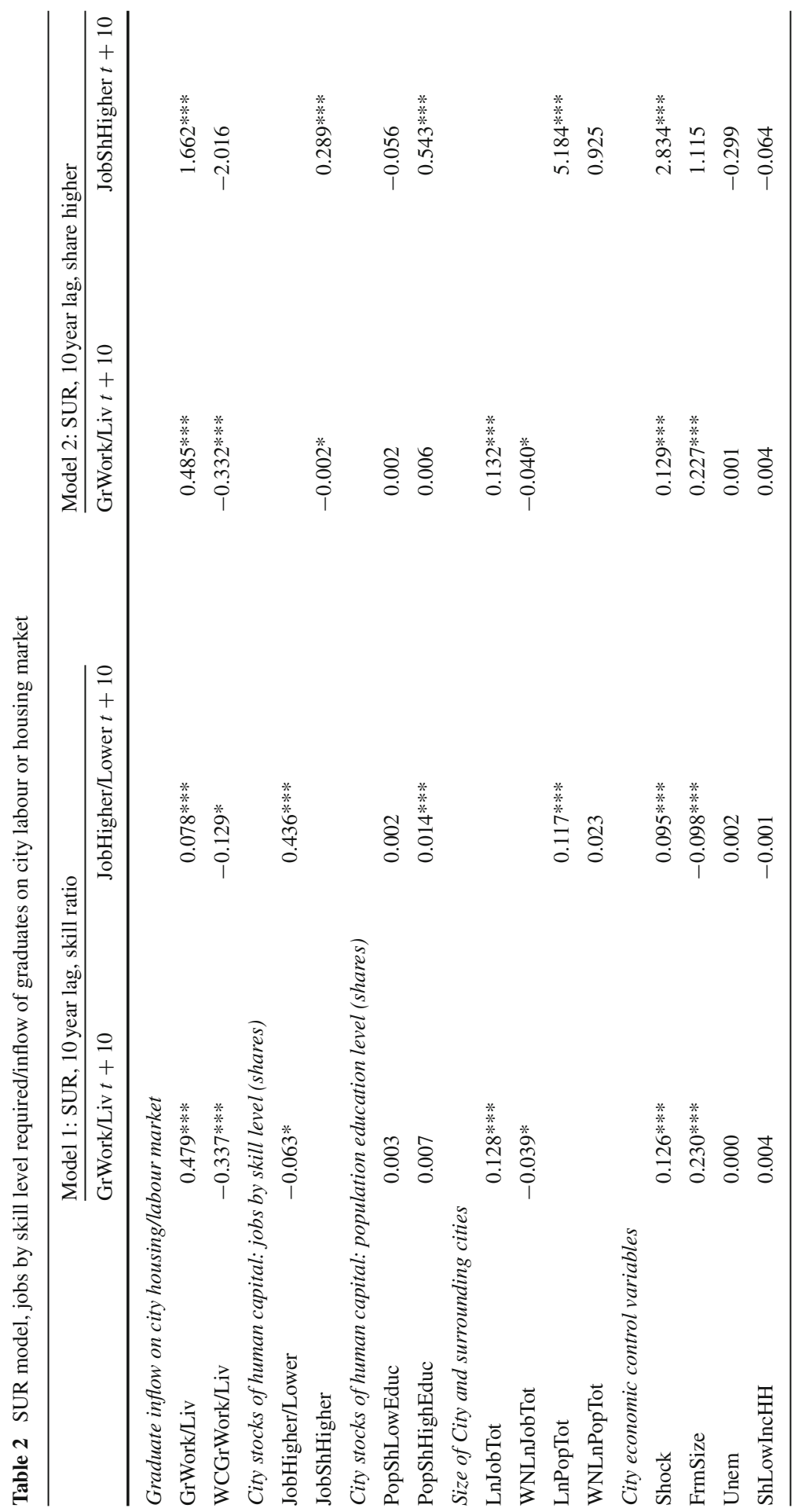




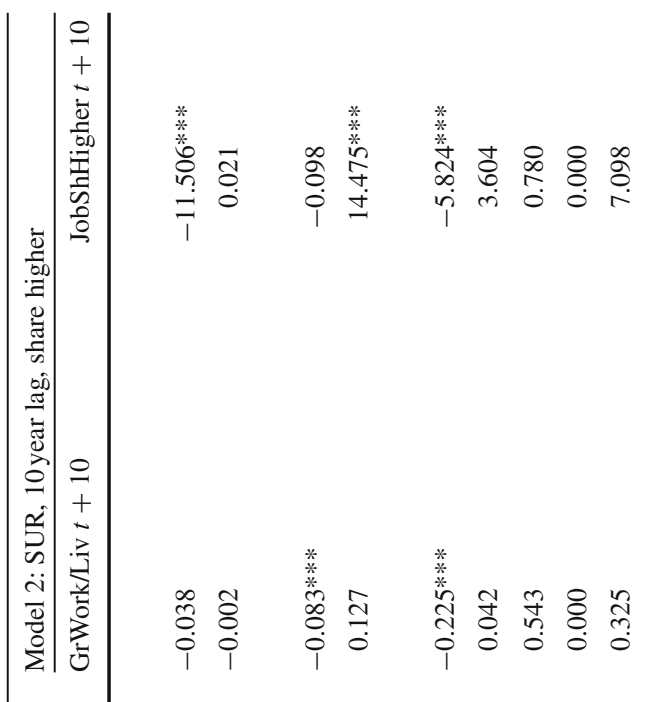

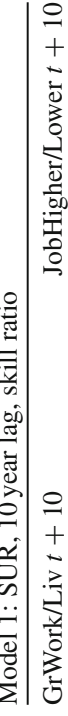

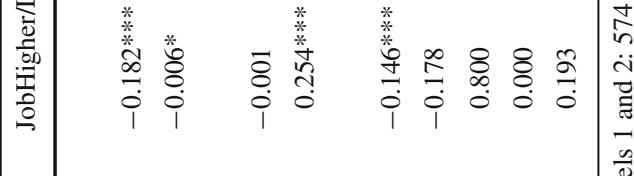

范

(a)

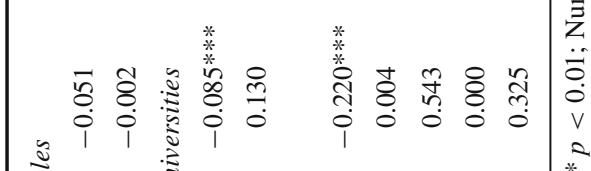

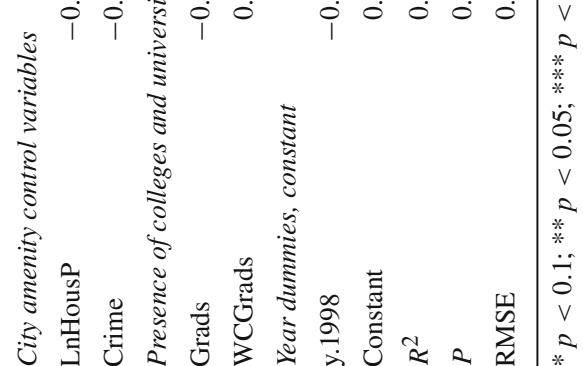


In that light, this finding is surprising. The effect is (marginally) significant over and above the effect of having a large labour market and other city-level economic control variables. If these controls indeed capture the job attractiveness of the city, our result here serves to indicate that, ceteris paribus, smarter cities are indeed slightly more attractive as residential destinations.

We control for the inflow of graduates in neighbouring cities. In Model 1 we find a marginally significant negative effect on the city skill structure, which underlines the finding of accumulation of skills in a limited number of cities. However, this result is not confirmed in Model 2. We find a negative effect of this variable in the GrWork/Liv equation. This reflects the commuting system around cities, in that a high residential inflow in surrounding cities is associated with a stronger labour market inflow in the city under study, and vice versa.

\subsection{The effect of existing city stocks of human capital}

Starting with the JobHigher/Lower equation, we have entered each city's skills structure for the base year in order to control for the effect of existing human capital stocks. We find highly significant and positive effects for this lagged dependent variable. The interpretation here is that jobs of higher or lower skill levels tend to be concentrated in the same cities over time, even after controlling for the presence of universities and colleges and the sector structure.

The equation also features the breakdown of education levels in the resident population. Relative to the share of residents with a medium education level, we find positive effects for having a population with a higher education level (PopShHighEduc) on the city job skill ratio. This finding contrasts with the result for GrWork/Liv- here consumption spillovers do predominantly remain within the skill group (higher skilled services).

Turning to the graduate human capital inflow equation, we find that the lagged dependent variable is also positive and highly significant. It implies a degree of dynamic stability: a city's ability to attract human capital to either its labour or its housing market depends strongly on having that ability in the past. We find no effects for the education structure of the resident population: having a relatively highly educated resident population as such does not lead to stronger residential or labour market inflows of graduates.

\subsection{Results for other exogenous control variables and covariates}

In this section, we discuss the results for the other control variables that were included in our models. We start with the effect of city size, before moving on to the variables pertaining to a city's economic and residential amenity qualities and the presence of higher education institutions.

\subsubsection{City and market size}

We controlled for city size by entering a city's population total, as well as those of neighbouring cities in the JobShHigher/Lower equation. In the GrWork/Liv equations, 
the total number of jobs in the city and those neighbouring were entered. These variables are intended to control for city, or market, size effects. We found that a city's size in terms of population positively affects its skill level. However, the population size of neighbouring cities is insignificant.

The total number of jobs within a city affects GrWork/Liv positively. In other words, cities with more jobs relatively strongly attract human capital to their labour opportunities rather than to their residential areas. This is not surprising as many studies have shown that young migrants and recent graduates are drawn to areas that have a large number of job opportunities. Likewise, we find that large cities nearby lead to a stronger residential function for graduates.

\subsubsection{City economic and residential controls}

The variable "Shock" transfers national employment growth to a city's sectoral structure. We find a positive effect on JobHigher/Lower, indicating that cities with a favourable sector structure tend to develop more high-end jobs. FirmSize affects JobHigher/Lower negatively, but is insignificant in Model 2. It indicates that the presence of large firms does not univocally lead to more employment opportunities for the higher skill groups. Both Shock and FirmSize are significant and positive in the GrWork/Liv equation. We would suggest that cities with large firms and favourable sectoral structures are attractive labour market destinations for recent graduates, which is not surprising.

The city unemployment rate and the share of low income households have no effect on either the skill ratio or the type of graduate inflow. Graduates may be affected in a limited way by the general unemployment conditions, as they usually decide to stay enrolled in university of college in adverse economic conditions. There is apparently no effect of a city's resident's low end purchasing power on a city's skills structure, with consumption effects mainly related to market size and the share of higher educated residents - this implies a high-end effect predominantly.

The next group of variables is used to reflect a city's residential qualities. LnHousP primarily reflects the cost of living in a city. Having controlled for the city's economic characteristics, it can be interpreted as a measurement of the demand for living in that city. Higher average house prices, or areas that are in residential demand, are associated with higher proportions of elementary to medium skilled jobs. We find no effect of this factor on the ability to attract graduate human capital to a city's labour and housing markets.

The crime rate in a city is only marginally significant and negatively associated with JobHigher/Lower. It is in line with the findings of Gottlieb (1995), who noted that residential amenities can have effects on city employment as employers of higher skilled workers take them into account in making location decisions. We do not confirm it in Model 2 however. One might have expected a positive effect on GrWork/Liv for crime as cities with higher crime rates attract fewer graduates to their residential markets, but apparently this does not play an important role for this particular group.

The presence of a university or college, measured as the number of graduates produced by institutions of higher education within the city (the variable "Grads"), has no effect on JobHigher/Lower. Further, having commuting ties with another city that has 
a university or college serves to increase the general skill levels found within a city's employment possibilities. The presence of a university or college has a negative effect on GrWork/Liv, suggesting that it boosts residential inflows more than labour market inflows. This could be the result of graduates electing to remain in their college or university town whilst working in their first job, which might be in that city or elsewhere.

\section{Conclusions}

In this paper we have studied the recursive relationship between a city's skills structure and the inflow of graduate human capital onto its labour and housing markets. Local policymakers devote much attention to retaining and attracting individuals with high human capital. Should policy makers be focussing on attracting graduate human capital to their labour markets or to their residential areas? Not much is known on how these inflows impact on the city's skills structure: are there only effects for the higher skilled, or do other groups stand to gain as well? And if so, can we ascribe these effects to either labour market based production spillovers, or to consumption spillovers stemming from the residential inflows? Furthermore, is the effect of graduate human capital inflows significant over and above the effects of existing city endowments of human capital, and the effects of neighbouring areas?

We have applied a dataset that allows us to study these issues for 287 larger Dutch municipalities, over the period 1998-2008, using a seemingly unrelated regression model. This allows to apply time lags reducing the problem of endogeneity between the city's skills structure and the attraction of graduate human capital, whilst taking any remaining correlations between the two equations into account. Critically, in this study we strictly distinguish between the place of work and of residence, in order to identify the different pathways in which both new graduate inflows as well as the activities of the incumbent population affect the outcomes.

Our main finding is that a relatively strong inflow onto city labour markets leads to an improved position of jobs for which a higher or scientific skill level is required, indicating a productivity spillover for this group. Further, the share of elementary to medium level jobs improves as a result of a relatively strong inflow on city residential markets. This in turn suggests the existence of consumption spillovers in Dutch cities.

Graduate inflows do not only cause changes in a city's skills structure; they are themselves influenced by this structure. However, having large proportions of higher and scientific-level jobs leads to modestly stronger inflow of recent graduates into city residential areas, not into its labour markets as one might have expected. Seeing as we find no effect on graduate inflows from having a large share of higher educated among the resident population, we must conclude that smart cities become attractive residential destinations only if these higher skills are actually applied locally, for example in higher skilled services.

Secondly, this paper demonstrates the value of carefully distinguishing between the skill levels required for the jobs located in the city and the education levels of the resident population. We have shown that these two stocks of human capital present in a city simultaneously influence the city's skills structure, either through production (jobs by skill level) effects or through consumption (resident population by education) 
effects. However, in contrast to graduate inflows, we found little evidence of positive spillovers between skills groups: the main effects are found to be a strengthening of the position of one's own skills group, especially "higher educated on higher skilled". This is in line with the idea of skills becoming concentrated in certain cities. The consumption effect of an inflow of recent graduates on the lower and medium skilled residents is thus the exception rather than the rule.

Thirdly, we have followed trends in the recent literature by including information on cities with which a commuting relationship exists. Further, we have included a market potential variable that takes into account the size of neighbouring cities. We found no spatial effects on the city skills structure, but being close to other cities which have large labour markets has increases the residential inflow of graduates for a given city. The presence of colleges and universities within commuting distance serves to increase the level of skills in a city.

This study also illustrates a point made in recent literature-that factors which may be thought of as purely economic strengths can in fact play a role in residential inflow, and vice versa. Distinguishing between city residents and workers, as this paper does, therefore serves to shed light on potentially countervailing effects. We find, for example, that high housing costs are associated with a city skill structure which leans more towards a lower skilled workforce. In gentrifying cities this might serve to alleviate some of the pressure on the lower skilled residents resulting from decreased housing affordability.

Our analysis demonstrates that there is plenty of scope to focus upon in attracting human capital flows to both a city's labour as well as its housing markets. However, many of the factors that were demonstrated to be of relevance in this study are difficult for policymakers in individual cities to influence, especially in the short term. Given some of the key mechanisms in play, policymakers should focus on establishing the role of their city in the wider region and the national urban hierarchy: employment centre or a predominantly residential function? It would appear that significant accumulation of skills, spiralling off production externalities, as observed for US metropolitan areas, is reserved for a rather select number of Dutch cities. Consumption spillovers are pivotal too, be it in different ways. It is tempting to speculate why especially a city's capacity to draw in graduates to its residential areas would lead to positive effects for the elementary to medium skilled, whereas a high share of higher educated in the incumbent resident population is more beneficial to those in higher skilled occupations. Perhaps here a life-course pattern in service demand plays a role, in particular as these recent graduates are predominantly in the household formation stage (Venhorst et al. 2013). Partners are found, who, more often than not, are also higher educated, and children are born. The extent to which these live events shape employment opportunities for other skill groups, through extra demand for household services, is left for future research, but it might serve as one of the pivotal mechanisms.

Open Access This article is distributed under the terms of the Creative Commons Attribution 4.0 International License (http://creativecommons.org/licenses/by/4.0/), which permits unrestricted use, distribution, and reproduction in any medium, provided you give appropriate credit to the original author(s) and the source, provide a link to the Creative Commons license, and indicate if changes were made. 


\section{Appendix 1: Variable descriptions and data sources}

In Table 3 below we present an overview of variable definitions and data sources. City-specific employment by the skill levels demanded by employers is not readily available for many Dutch cities. ${ }^{11}$ We therefore derive this information from the Working Conditions Survey (WCS $)^{12}$ produced by the Dutch Ministry of Social Affairs and Employment, a process that involves three steps.

In the WCS, the location of a firm is reported at the level of two-digit postcode areas, of which there are a total of 90 in the Netherlands. In the first step, for each two-digit postcode area, the skills structure of employment is derived from the WCS for each single-digit NACE sector. The data for a given year is based on a three-year moving average. The skills structure is recorded in the WCS using an internal classification, but this can be converted to the Statistics Netherlands SBC-'92/2001 classification, which in turn is related to the International Standard Classification of Occupations 1988 (ISCO). We use five mutually exclusive levels: jobs requiring elementary, lower, medium, higher and scientific skills. This first step results in information on the skills structure of employment, for each single-digit NACE sector, in each of the 90 doubledigit postcode areas.

In this study, the focus is on cities (municipalities), the administrative units that local policymakers are generally working with. However, each two-digit postcode area usually contains more than one municipality or parts thereof. Therefore, in a second step, municipalities are assigned to the two-digit postal code area in which the largest proportion of their residents live. In a few instances, a large city will fully occupy a two-digit postcode area.

In the third step, the sector-specific skills structure (in terms of shares) for a given two-digit postcode is then assigned to the cities, deemed to fall within that area, by multiplying the proportions in these sectors by the number of workers. ${ }^{13}$ This results in the city-specific job totals by skill level required. From this, we then compute the skills shares (variables JobHigher/Lower and JobShHigher) that we use in this study to describe the city skills structure. ${ }^{14}$

This approach minimises the degree of assumed spatial dependency. Rather than assuming that the skills structure is the same for all cities that share the same two-

\footnotetext{
11 Based on the Labour Force Survey (EBB). Statistics Netherlands provides information on worker education level for large Dutch cities, but this information is geo-referenced according to the residence of the worker involved, not the location of the job.

12 In Dutch: Arbeidsvoorwaarden Onderzoek (AVO). This survey, undertaken from 1992 onwards, is a representative annual cross section of firms and their employees,. On average a survey covers 37,000 employees in 2000 firms.

13 The number of workers per single-digit NACE sector in a city was computed using Statistics Netherlands microdata (SSB-Banen).

14 The city-specific education levels, for employees working in that city, applied in the models in "Appendix 2 " were derived in a similar fashion. The education level by worker occupying a job located in a given city is based on the Dutch version of the international ISCED classification, and is divided into low (ISCED 0-2), medium (ISCED 3 and 4) and high (ISCED 5 and 6) levels. The WCS survey under-reports the public sector (government, education). The data were therefore enriched using the ROA-SIS graduate survey from which the skills structure for these NACE sectors was derived at the regional level.
} 
Table 3 Variable descriptions and data sources

\begin{tabular}{|c|c|c|}
\hline Name & Description & Data source \\
\hline JobHigher/Lower & $\begin{array}{l}\text { Number of city jobs of higher and scientific skill level } \\
\text { relative to number of city jobs of medium, lower and } \\
\text { elementary level }\end{array}$ & 1 \\
\hline JobShHigher & Share of city jobs of higher and scientific level & 1 \\
\hline GrWork/Liv & $\begin{array}{l}\text { Recent graduates entering city labour market/city } \\
\text { housing market }\end{array}$ & 4,2 \\
\hline WCGrWork/Liv & $\begin{array}{l}\text { Spatial lag of GrWork/Liv using row-normalised } \\
\text { commuting matrix }\end{array}$ & 4,2 \\
\hline PopShLowEd & Share of city population with lower education level & 1 \\
\hline PopShMedEd & Share of city population with medium education level & 1 \\
\hline PopShHighEd & Share of city population with higher education level & 1 \\
\hline LnPopTot & $\ln$ (Total city population) & 1 \\
\hline WNLnPopTot & $\begin{array}{l}\text { Spatial lag of LnPopTot using first-order queen } \\
\text { contiguity matrix }\end{array}$ & 1 \\
\hline LnJobTot & $\ln$ (Total number of city jobs) & 1 \\
\hline WNLnJobTot & $\begin{array}{l}\text { Spatial lag of LnJobTot using first-order queen } \\
\text { contiguity matrix }\end{array}$ & 1 \\
\hline Shock & $\begin{array}{l}\text { National sector-specific employment growth, reweighed } \\
\text { according to city sector structure (Katz and Murphy } \\
\text { 1992) }\end{array}$ & 3 \\
\hline FrmSize & $\begin{array}{l}\text { City average number of employees per firm } \\
\text { establishment }\end{array}$ & 3 \\
\hline Unem & Unemployment rate & 2 \\
\hline ShLowIncHH & Share of city households with low income & 2 \\
\hline LnHousP & $\ln$ (City average housing value, relative to national mean) & 2 \\
\hline Crime & Crime suspects, per 1000 of the city population & 2 \\
\hline Grads & $\begin{array}{l}\text { Number of graduates from city university and } \\
\text { vocational colleges }\end{array}$ & 4 \\
\hline WCGrads & $\begin{array}{l}\text { Spatial lag of Grads using row-normalised commuting } \\
\text { matrix }\end{array}$ & 4 \\
\hline \multicolumn{3}{|l|}{ Data sources } \\
\hline 1 & $\begin{array}{l}\text { Statistics Netherlands (Labour Survey); AVO; own } \\
\text { computations }\end{array}$ & \\
\hline 2 & Statistics Netherlands & \\
\hline 3 & LISA Registry of Firms & \\
\hline 4 & ROA-SIS, own computations & \\
\hline
\end{tabular}

digit postcode, we only assume that the skills structure in a given sector, in a given year, is the same across a two-digit postcode region. In addition, the degree of spatial dependency is likely to be higher in small municipalities. More of these municipalities would share the same two-digit postcode, and as a result would have the same skill structure assigned to them. Therefore, and for other data-related reasons, we have focussed this study on a subset of the 287 larger municipalities out of the total of 
441 (as of January 2009). Our selection is based on cities that had more than 10,000 inhabitants over the entire study period, plus available data. Our approach does not allow an analysis of city employment by sector, as in Blien et al. (2006) and Glaeser et al. (1992), as the city's skills structure is determined from the sector structure. The sectoral structure is controlled for in our modelling approach.

We use the ROA School-leaver Information System (ROA-SIS) dataset (available for 1997-2008) to compute the relative flows of graduates towards a city's labour and housing markets (variable "GrWork/Liv"). However, the inflow of graduates to a city's residential areas could not be based directly on those data because information on residential locations was only included for the period 2005 to 2008. Instead, we applied Statistics Netherlands data on migration by age, selecting only migrants aged 20-25 since this covers the age group in which most graduates receive their college and university diplomas. Even though correlations with the available graduate-based information are very high (at around 95\%), it is likely to constitute some degree of overestimation of the true graduate flows. However, given the use of the variable within the context of this study (relative attraction to labour and housing markets) this issue is of limited consequence.

\section{Appendix 2: Robustness checks, 1 year lag versions}

In Table 4 we present sample statistics for the 1 year lag variety of our analysis. Subsequently, in Table 5, the estimation results are presented.

Table 4 Sample statistics, 1 year lag variety

\begin{tabular}{|c|c|c|c|c|c|c|c|c|}
\hline & \multicolumn{4}{|l|}{ Year $t$} & \multicolumn{4}{|c|}{ Year $t+1$} \\
\hline & Mean & SD & Min & Max & Mean & SD & Min & Max \\
\hline \multicolumn{9}{|c|}{ Graduate inflow on city housing/labour market } \\
\hline GrWork/Liv & 0.78 & 0.49 & 0.00 & 4.25 & 0.80 & 0.50 & 0.00 & 4.25 \\
\hline WCGrWork/Liv & 0.80 & 0.19 & 0.24 & 1.47 & & & & \\
\hline \multicolumn{9}{|c|}{ City stocks of human capital: jobs by skill level (shares) } \\
\hline JobHigher/lower & 0.32 & 0.37 & 0.02 & 4.60 & 0.32 & 0.36 & 0.02 & 4.60 \\
\hline JobShHigherSk & 20.78 & 13.72 & 2.19 & 82.15 & 21.08 & 13.68 & 2.19 & 82.15 \\
\hline \multicolumn{9}{|c|}{ City stocks of human capital: population education level (shares) } \\
\hline PopShLowEduc & 36.65 & 6.79 & 16.53 & 61.21 & & & & \\
\hline PopShMedEduc (omitted) & 42.46 & 4.23 & 29.46 & 57.98 & & & & \\
\hline PopShHighEduc & 20.90 & 7.38 & 6.00 & 53.49 & & & & \\
\hline \multicolumn{9}{|c|}{ Size of City and surrounding cities } \\
\hline LnPopTot & -1.04 & 0.68 & -2.23 & 2.01 & & & & \\
\hline WNLnPopTot & -0.90 & 0.60 & -2.63 & 0.97 & & & & \\
\hline LnJobTot & -2.05 & 0.87 & -3.99 & 1.52 & & & & \\
\hline WNLnJobTot & -1.78 & 0.77 & -3.65 & 0.50 & & & & \\
\hline
\end{tabular}


Table 4 continued

\begin{tabular}{|c|c|c|c|c|c|c|c|c|}
\hline & \multicolumn{4}{|l|}{ Year $t$} & \multicolumn{4}{|c|}{ Year $t+1$} \\
\hline & Mean & SD & Min & Max & Mean & SD & Min & $\operatorname{Max}$ \\
\hline \multicolumn{9}{|c|}{ City economic control variables } \\
\hline Shock & 1.68 & 1.68 & -2.95 & 6.02 & & & & \\
\hline FrmSize & 0.93 & 0.31 & 0.33 & 2.34 & & & & \\
\hline Unem & 4.45 & 1.94 & 0.00 & 14.01 & & & & \\
\hline ShLowIncHH & 27.54 & 4.36 & 15.00 & 40.41 & & & & \\
\hline \multicolumn{9}{|c|}{ City amenity control variables } \\
\hline LnHousP & 0.07 & 0.23 & -0.66 & 1.00 & & & & \\
\hline Crime & 9.86 & 4.27 & 0.25 & 31.00 & & & & \\
\hline \multicolumn{9}{|c|}{ Presence of colleges and universities } \\
\hline Grads & 0.21 & 0.83 & 0.00 & 8.57 & & & & \\
\hline WCGrads & 0.81 & 0.30 & 0.12 & 1.99 & & & & \\
\hline
\end{tabular}

Number of cases: 3130

Table 5 Estimates

Model 1B: SUR, 1 year lag, skill ratio Model 2B: SUR, 1 year lag, share higher

GrWork/Liv $t+1$ JobHigher/Lower $t+1$ GrWork/Liv $t+1$ JobShHigher $t+1$

Graduate inflow on city housing/labour market

$\begin{array}{lllrl}\text { GrWork/Liv } & 0.714 * * * & 0.014 * * & 0.716^{* * *} & 0.486 * * \\ \text { WCGrWork/Liv } & -0.105^{* *} & 0.008 & -0.113^{* * *} & 0.644\end{array}$

City stocks of human capital: jobs by skill level (shares)

JobHigher/Lower $-0.023 * \quad 0.876^{* * *}$

JobShHigher

0.000

$0.852 * * *$

City stocks of human capital: population education level (shares)

\begin{tabular}{|c|c|c|c|c|}
\hline PopShLowEduc & 0.001 & 0.000 & 0.001 & -0.026 \\
\hline PopShHighEduc & $0.005^{* * *} *$ & $0.004 * * *$ & $0.004 * *$ & $0.125 * * *$ \\
\hline \multicolumn{5}{|c|}{ Size of City and surrounding cities } \\
\hline LnJobTot & $0.084 * * *$ & & $0.082 * * *$ & \\
\hline WNLnJobTot & -0.003 & & -0.005 & \\
\hline LnPopTot & & 0.010 & & $0.747 * * *$ \\
\hline WNLnPopTot & & $0.011 * *$ & & 0.226 \\
\hline \multicolumn{5}{|c|}{ City economic control variables } \\
\hline Shock & $0.039 * * *$ & $-0.015 * *$ & $0.038 * * *$ & -0.280 \\
\hline FrmSize & $0.074 * * *$ & 0.003 & $0.066 * * *$ & $0.735^{* *}$ \\
\hline Unem & 0.001 & 0.000 & 0.002 & 0.065 \\
\hline ShLowIncHH & $0.005^{* *} *$ & 0.001 & $0.004 * *$ & -0.019 \\
\hline
\end{tabular}


Table 5 continued

\begin{tabular}{|c|c|c|c|c|}
\hline & \multicolumn{2}{|c|}{ Model 1B: SUR, 1 year lag, skill ratio } & \multicolumn{2}{|c|}{$\underline{\text { Model 2B: SUR, } 1 \text { year lag, share higher }}$} \\
\hline & GrWork/Liv $t+1$ & JobHigher/Lower $\mathrm{t}+1$ & GrWork/Liv $t+1$ & JobShHigher $\mathrm{t}+1$ \\
\hline \multicolumn{5}{|c|}{ City amenity control variables } \\
\hline LnHousP & 0.032 & $-0.053 * * *$ & 0.042 & $-2.040 * * *$ \\
\hline Crime & $-0.003 *$ & 0.001 & $-0.003 *$ & 0.040 \\
\hline \multicolumn{5}{|c|}{ Presence of colleges and universities } \\
\hline Grads & $-0.036^{* * *}$ & 0.002 & $-0.035^{* * *}$ & 0.021 \\
\hline WCGrads & 0.037 & $0.025 *$ & 0.033 & $1.508 * * *$ \\
\hline \multicolumn{5}{|c|}{ Year dummies, constant } \\
\hline y.1998 & $-0.206^{* * *}$ & 0.015 & $-0.203 * * *$ & -0.238 \\
\hline y.1999 & $-0.133 * * *$ & $-0.034 * *$ & $-0.128 * * *$ & $-1.105^{*}$ \\
\hline y.2000 & $-0.080 * * *$ & $-0.029 *$ & $-0.074 * *$ & $-1.654 * * *$ \\
\hline y.2001 & $-0.186^{* * *}$ & $-0.052 * * *$ & $-0.181 * * *$ & $-1.529 * * *$ \\
\hline y.2002 & $-0.141 * * *$ & $-0.076^{* * *}$ & $-0.136 * * *$ & $-1.625^{* *}$ \\
\hline у.2003 & 0.030 & $-0.112^{* * *} *$ & 0.034 & $-2.566^{* * * *}$ \\
\hline у.2004 & -0.069 & $-0.100 * * *$ & -0.063 & $-2.956^{* * * *}$ \\
\hline y.2005 & -0.018 & $-0.122 * * *$ & -0.011 & $-3.789 * * *$ \\
\hline у.2006 & $-0.088^{* *}$ & $-0.088 * * *$ & $-0.078^{*}$ & $-2.759 * * *$ \\
\hline y.2007 & $-0.112 * * *$ & $-0.038 * *$ & $-0.101 * * *$ & $-1.591 * * *$ \\
\hline Constant & $0.193^{*}$ & 0.015 & $0.206^{*}$ & 2.211 \\
\hline$R^{2}$ & 0.688 & 0.911 & 0.688 & 0.905 \\
\hline$P$ & 0.000 & 0.000 & 0.000 & 0.000 \\
\hline RMSE & 0.279 & 0.144 & 0.279 & 5.016 \\
\hline
\end{tabular}

$* p<0.1 ; * * p<0.05 ; * * * p<0.01$; Number of cases in model 1B and 2B: 3130

\section{References}

Acemoglu D, Angrist J (2000) How large are human capital externalities? Evidence from compulsory schooling laws. NBER Macroecon Annu 15:9-59

Berry CR, Glaeser EL (2005) The divergence of human capital levels across cities. Pap Reg Sci 83(3):407444

Bils M, Klenow PJ (2000) Does schooling cause growth? Am Econ Rev 90(5):1160-1183

Blien U, Suedekum J, Wolf K (2006) Local employment growth in West Germany: a dynamic panel approach. Labour Econ 13(4):445-458

Boarnet MG (1994) The monocentric model and employment location. J Urban Econ 36(1):79-97

Boarnet MG, Chalermpong S, Geho E (2005) Specification issues in models of population and employment growth. Pap Reg Sci 84(1):21-46

Broersma L, Edzes A, van Dijk J (2015) Human capital externalities: effects for low educated workers and low skilled jobs. Reg Stud. doi:10.1080/00343404.2015.1053446

Carlino GA, Mills ES (1987) The determinants of country growth. J Reg Sci 27(1):39-54

Combes P, Magnac T, Robin J (2004) The dynamics of local employment in France. J Urban Econ 56(2):217243

Di Pietro G, Urwin P (2006) Education and skills mismatch in the Italian graduate labour market. Appl Econ 38:79-93

Duranton G, Puga D (2004) Microfoundations of urban agglomeration economies. In: Henderson JV, Thisse JF (eds) Handbook of urban and regional economics. Elsevier B.V, North Holland 
Faggian A, McCann P (2006) Human capital flows and regional knowledge assets: a simultaneous equation approach. Oxf Econ Pap 52:475-500

Faggian A, McCann P (2008) Human capital, graduate migration and innovation in british regions. Camb J Econ 33(2):317-333

Faggian A, McCann P (2009) Human capital and regional development. In: Capello R, Nijkamp P (eds) Handbook of regional growth and development theories. Edward Elgar, Cheltenham, pp 133-151

Florax RJGM, Folmer H (1992) Specification and estimation of spatial linear regression models: Monte Carlo evaluation of pre-test estimators. Reg Sci Urban Econ 22:405-432

Glaeser EL (1999) Learning in cities. J Urban Econ 46(2):254-277

Glaeser EL, Gottlieb PD (2006) Urban resurgence and the consumer city. Urban Stud 8:1275-1299

Glaeser EL, Kallal HD, Scheinkman JA, Shleifer A (1992) Growth in cities. J Polit Econ 100(6):1126-1152

Glaeser EL, Kolko J, Saiz A (2001) Consumer city. J Econ Geogr 1:27-50

Glaeser EL, Maré DC (2001) Cities and skills. J Labor Econ 19(2):316-342

Glaeser EL, Saiz A (2004) The rise of the skilled city. In: Brookings-Wharton papers on urban affairs, pp 47-105

Glaeser EL, Scheinkman JA, Shleifer A (1995) Economic growth in a cross-section of cities. J Monet Econ 36(1):117-143

Gottlieb PD (1995) Residential amenities, firm location and economic development. Urban Stud 32(9):1413-1436

Hoogstra GJ, Van Dijk J, Florax RJGM (2011) Determinants of variation in population-employment interaction findings: a quasi-experimental meta-analysis. Geogr Anal 43(1):14-37

Hoogstra GJ, Florax RJGM, Van Dijk J (2005) Do ‘jobs follow people’ or 'people follow jobs'? A metaanalysis of Carlino-Mills studies. In: 45th Conference of the European Regional Science Association, Amsterdam

Jovanovic B, Rob R (1989) The growth and diffusion of knowledge. Rev Econ Stud 56(4):569-582

Katz LF, Murphy KM (1992) Changes in relative wages, 1963-1987: supply and demand factors. Q J Econ 107(1):35-78

Krugman P (1991) Increasing returns and economic geography. J Polit Econ 99(3):483-499

Lucas RE (1988) On the mechanics of economic development. J Monet Econ 22:3-42

Marlet G, Van Woerkens C (2007) The Dutch creative class and how it fosters urban employment growth. Urban Stud 44(13):2605-2626

Moretti E (2004a) Estimating the social return to higher education: evidence from longitudinal and repeated cross-sectional data. J Econom 121:175-212

Moretti E (2004b) Human capital externalities in cities. In: Henderson JV, Thisse JF (eds) Handbook of urban and regional economics. Elsevier B.V, North Holland

Moretti E (2004c) Workers' education, spillovers, and productivity: evidence from plant-level production functions. Am Econ Rev 94(3):656-690

Nijkamp P, Poot J (1998) Spatial perspectives on new theories of economic growth. Ann Reg Sci 32:7-37

Partridge M, Bollman RD, Olfert MR, Alasia A (2007a) Riding the wave of urban growth in the countryside: spread, backwash, or stagnation? Land Econ 83(2):128-152

Partridge M, Olfert MR, Alasia A (2007b) Canadian cities as regional engines of growth: agglomeration and amenities. Can J Econ 40(1):39-68

Poelhekke S (2006) Do amenities and diversity encourage city growth? A link through skilled labor. European University Institute Working Papers, 2006-10

Rauch JE (1991) Productivity gains from geographic concentration of human capital: evidence from the cities. National Bureau of Economic Research, Cambridge

Rodríguez-Pose A, Vilalta-Bufí M (2005) Education, migration, and job satisfaction: the regional returns of human capital in the EU. J Econ Geogr 5:545-566

Sassen S (2001) The global city: New York, London. Princeton University Press, New Jersey

Schlitte F (2010) Local human capital, segregation by skill, and skill-specific employment growth. In: IAB discussion paper series, 22/2010. IAB, Bonn, Germany

Shapiro JM (2006) Smart cities: quality of life, productivity and the growth effects of human capital. Rev Econ Stat 88(2):324-335

Storper M, Scott AJ (2009) Rethinking human capital, creativity and urban growth. J Econ Geogr 9:147-167

Suedekum J, Blien U (2005) Local economic structure and industry development in Germany, 1993-2001. Econ Bull 15(17):1-8 
Suedekum J (2009) Convergence of the skill composition across German regions. Reg Sci Urban Econ 38:148-159

Venhorst VA, Van Dijk J, Van Wissen LJG (2011a) An analysis of trends in spatial mobility of Dutch graduates. Spat Econ Anal 6(1):57-82

Venhorst VA, Edzes AJE, Broersma L, Van Dijk J (2011b) Brain drain of brain gain?. Hoger opgeleiden in grote steden in Nederland, Nicis Institute, Den Haag

Venhorst VA, Koster S, Van Dijk J (2013) Geslaagd in de Stad. URSI Research Report no 344. University of Groningen. Available at: http://irs.ub.rug.nl/ppn/37257274X

Venhorst VA, McCann P (2015) Graduate early career and labour market mobility: a road to success in dense and less-dense regions? ERSA conference 2015, 25th-28th of August, Lisbon, Portugal 